\title{
Bayesian Network Analysis of Lysine Biosynthesis Pathway in Rice
}

\author{
Aditya Lahiri ${ }^{1, *}++^{(D}$, Khushboo Rastogi ${ }^{2,3} \mathbb{D}$, Aniruddha Datta ${ }^{1}\left(\mathbb{D}\right.$ and Endang M. Septiningsih ${ }^{2,3}(\mathbb{D}$ \\ 1 Department of Electrical and Computer Engineering, Texas A\&M University, College Station, TX 77843, USA; \\ datta@ece.tamu.edu \\ 2 Department of Soil and Crop Sciences, Texas A\&M University, College Station, TX 77843, USA; \\ khushboorastogi5@tamu.edu (K.R.); eseptiningsih@tamu.edu (E.M.S.) \\ 3 Genetics Interdisciplinary Program, Texas A\&M University, College Station, TX 77843, USA \\ * Correspondence: adi441994@gmail.com; Tel.: +1-832-782-4580
}

Citation: Lahiri, A.; Rastogi, K.;

Datta, A; Septiningsih, E.M. Bayesian

Network Analysis of Lysine

Biosynthesis Pathway in Rice.

Inventions 2021, 6, 37. https://

doi.org/10.3390/inventions6020037

Academic Editor: Konstantinos G.

Arvanitis

Received: 9 April 2021

Accepted: 19 May 2021

Published: 24 May 2021

Publisher's Note: MDPI stays neutral with regard to jurisdictional claims in published maps and institutional affiliations.

Copyright: (c) 2021 by the authors. Licensee MDPI, Basel, Switzerland. This article is an open access article distributed under the terms and conditions of the Creative Commons Attribution (CC BY) license (https:// creativecommons.org/licenses/by/ $4.0 /)$.
Abstract: Lysine is the first limiting essential amino acid in rice because it is present in the lowest quantity compared to all the other amino acids. Amino acids are the building block of proteins and play an essential role in maintaining the human body's healthy functioning. Rice is a staple food for more than half of the global population; thus, increasing the lysine content in rice will help improve global health. In this paper, we studied the lysine biosynthesis pathway in rice (Oryza sativa) to identify the regulators of the lysine reporter gene LYSA (LOC_Os02g24354). Genetically intervening at the regulators has the potential to increase the overall lysine content in rice. We modeled the lysine biosynthesis pathway in rice seedlings under normal and saline $(\mathrm{NaCl})$ stress conditions using Bayesian networks. We estimated the model parameters using experimental data and identified the gene DAPF(LOC_Os12g37960) as a positive regulator of the lysine reporter gene LYSA under both normal and saline stress conditions. Based on this analysis, we conclude that the gene DAPF is a potent candidate for genetic intervention. Upregulating DAPF using methods such as CRISPR-Cas9 gene editing strategy has the potential to upregulate the lysine reporter gene LYSA and increase the overall lysine content in rice.

Keywords: lysine; rice; amino acids; saline stress; abiotic stress; gene regulatory network; Bayesian network; parameter estimation; inference; RNA Seq

\section{Introduction}

\subsection{Background}

Proteins are one of the primary building blocks of all life on Earth and are present in every cell in the human body. Proteins are a crucial macronutrient in the human diet; they help build and repair cells and are essential for the human body's growth and development [1]. Proteins are comprised of long chains of amino acids; once the human body digests the proteins, they are broken down into their constituent amino acids [2]. There are twenty naturally existing amino acids that encode the 20,000 (approximate) unique proteins in the human body [3]. Among these amino acids, nine are classified as essential, and eleven are classified as nonessential [2,3]. Amino acids produced by the human body are considered nonessential, whereas the amino acids that cannot be synthesized by the body are considered essential [3]. Essential amino acids include phenylalanine, valine, tryptophan, threonine, isoleucine, methionine, histidine, leucine, and lysine [4]. Since essential amino acids cannot be synthesized, they need to be introduced to the human body through diets rich in complete proteins. A protein food source is considered a complete protein if it contains all the essential amino acids [5]. Typically, animal-based proteins are considered sources of complete protein. Plant-based proteins are considered incomplete as they do not contain all the essential amino acids $[5,6]$. 
According to the National Academy of Medicine, the recommended dietary allowance (RDA) of protein intake is $0.8 \mathrm{~g} / \mathrm{kg} /$ day $[7,8]$. A diet deficient in protein can cause edema, thinning of hair, and muscle mass loss in adults [9]. Though protein deficiency is rare in the developed world, it is still prevalent in impoverished and underdeveloped countries, especially among children $[9,10]$. Plant-based proteins accounted for $57 \%$ of the global protein supply and were followed by animal-based proteins such as meat and dairy, which accounted for $18 \%$ and $10 \%$, respectively [11]. Even though plant-based proteins constitute a majority of the global protein supply, according to the World Health Organization (WHO), the demand for animal-based protein has been on the rise due to urbanization, population growth, and rising economies. The WHO predicts that annual meat production will reach 376 million tons by 2030, a 72\% increase from 1997-1999, when the yearly meat production was 218 million tons [12]. This global increase has placed a burden on the livestock sector, especially in Europe and the Americas, where animal-based protein intake is higher than that of plant-based proteins [13]. In the USA and European countries, proteins from animalbased sources ranged from $55 \%$ to $71 \%$ (depending on countries) of the total protein intake, a significant proportion of which were from red meat [14].

Animal-based protein sources such as meat, milk, and eggs are richer in essential amino acids and have a higher food protein quality in terms of digestibility, net protein utilization, and biological value compared to plant-based protein sources such as legumes and cereals [13]. However, animal-based proteins, specifically processed and red meats, have been linked with cancer, type 2 diabetes, and cardiovascular diseases [15-17]. Apart from health concerns, proteins sourced from animals have a significant impact on climate change. According to the Food and Agriculture Organization of the United Nations, the livestock supply chain accounts for $14.5 \%$ of global anthropogenic greenhouse gas emissions [18]. With the global population set to reach 9.8 billion by 2050 and the increasing demand for animal-based proteins, the challenges associated with food security and climate change will only be exacerbated [12,19]. Hence, a shift toward plant-based protein sources may help reduce the carbon footprint, risks of chronic illness, and food security. While plant-based proteins may not contain all the necessary essential amino acids, a diet containing a diverse range of plant proteins can help overcome this limitation [20]. Cereal plants such as wheat, rice, and maize constitute the primary protein sources in developing countries [21,22]. With the majority of the world's population living in developing countries, it will therefore be beneficial to increase the protein content in cereal plants to ensure food security and prevent malnutrition.

\subsection{Lysine Content in Rice}

Lysine is produced in the aspartate pathway along with three other essential amino acids: threonine, methionine, and isoleucine [23]. Lysine is also the first limiting essential amino acid in cereal and legume crops because it is present in the lowest quantity [23-25]. This is why lysine deficiency is a common problem in developing nations that rely heavily on cereal crops $[23,26]$. A lysine deficient diet can reduce immunity, decrease protein levels in the blood, and cause retardation of mental and physical development in children [24]. Rice is a cereal plant that is an important food source for more than $50 \%$ of the global population [27]. About $95 \%$ of global rice is produced in developing countries, among which $92 \%$ are countries in Asia [28]. Rice accounts for $50 \%$ of the dietary caloric supply for 520 million living in poverty in Asia [29]. Like most cereal crops, rice is deficient in lysine, so in this study, we are interested in identifying the genetic regulators of lysine production in rice, since intervening at these regulators has the potential to increase the free lysine content in rice grains [30]. Enriching lysine content in rice will be a step toward ensuring food security and preventing malnutrition, especially in the vulnerable segments of the global population.

Over the last 50 years, lysine metabolism has been extensively studied. It has been shown that lysine is a self-regulating amino acid as the lysine biosynthesis pathway has two inhibition feedback loops [31-33]. These feedback loops are activated by the free lysine content, which negatively regulates the enzymes dihydrodipicolinate synthase (DHPS) and 
aspartate kinase (AK) [24,34]. AK is the first enzyme of the lysine biosynthesis pathway and is also inhibited by threonine, another essential amino acid synthesized by the aspartate pathway $[24,34]$. Lysine is also degraded through the enzymes lysine ketoglutarate reductase (LKR) and saccharopine dehydrogenase (SDH) bifunctional enzymes [34]. The LKR and SDH enzymes are present in the saccharopine pathway and they initiate the lysine catabolism process through the TCA cycle (tricarboxylic acid cycle) [24]. The metabolic pathway of lysine biosynthesis and catabolism in presented in Figure 1 [31-33]. Thus, lysine can be enriched in cereal plants by enhancing its production in the biosynthesis pathway, preventing its catabolism, or combining these two approaches. A study by Long et al. (2013) focused on enhancing lysine through metabolic engineering of rice. These transgenic lines of rice overexpressed AK and DHPS. They observed that LKR and SDH levels were significantly higher in seeds of these rice lines, implying that the catabolic enzymes LKR and SDH were counteracting the effects of transgene AK and DHPS [33]. This method increased the free lysine content by 1.1 times in transgenic lines compared to the wild type. This study also implemented an LKR-RNAi line, which showed a 10-fold increase in lysine content, and a combination of LKR-RNAi with AK/DHPS overexpressing lines led to a 60-fold increase in free lysine content. In a different study, Yang et al. (2016) developed two pyramid transgenic lines in rice. The lysine content in these transgenic lines showed increased lysine content up to 25 -fold. This was achieved by enhancing the biosynthesis pathway and suppressing the catabolism pathway at the same time [35]. Unlike many lysine enhancement studies, which lead to reduced yield, oil content, and phenotype change, no significant trait changes were observed in this case, and the developed transgenic rice was deemed favorable for commercialization [36-38].

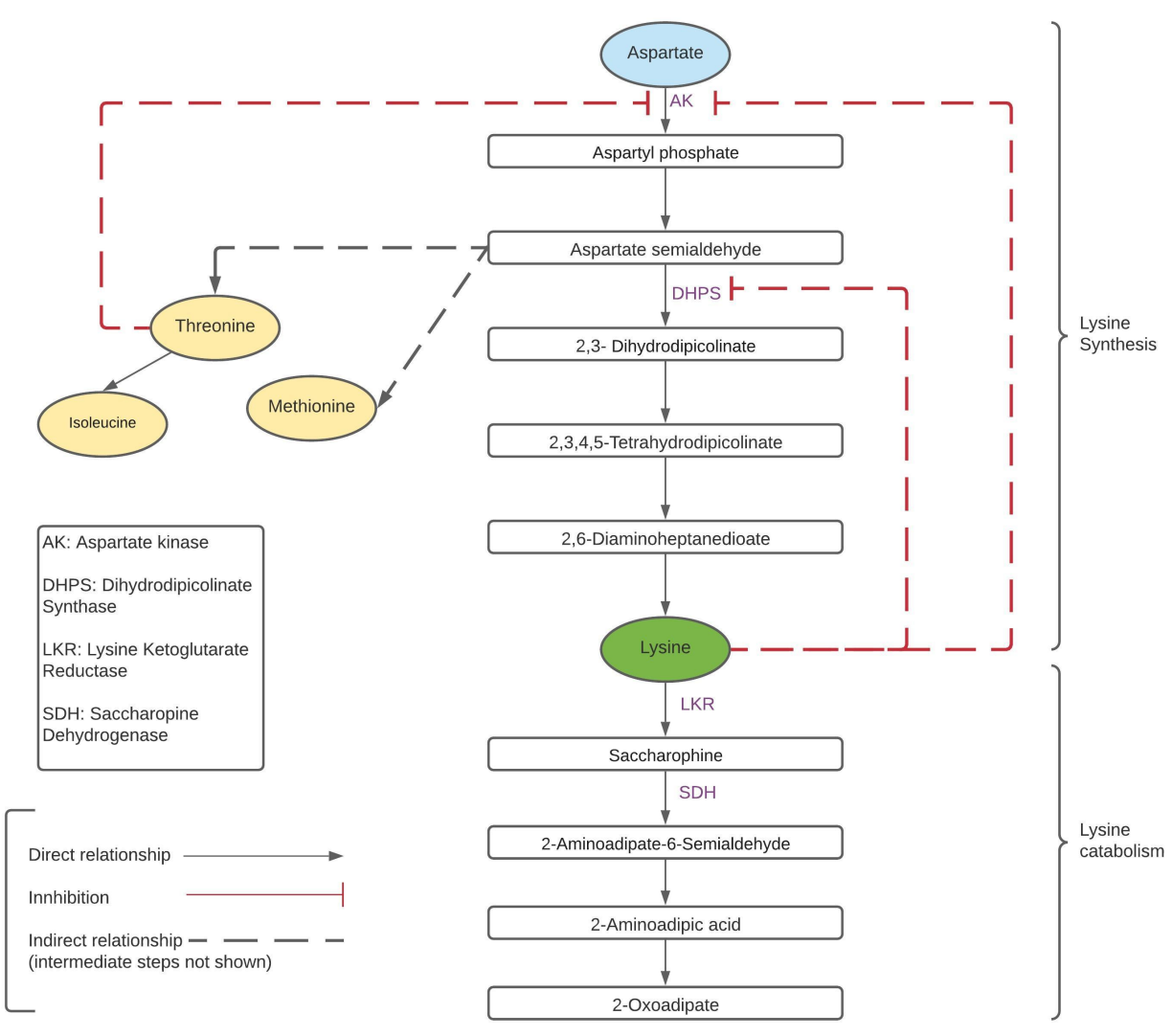

Figure 1. Lysine metabolic pathway for synthesis and catabolism.

While these studies have demonstrated that lysine content can be enhanced through careful metabolic engineering of high-lysine transgenic lines, these are not yet commercialized. Furthermore, transgenic crops rely on introducing foreign genes (transgenes) into 
the host crop, making them vulnerable to public acceptance. That is why, in this paper, we are interested in understanding the underlying genetic regulatory networks (GRNs) that govern these complex interactions. The GRNs can help us identify the genetic regulators of lysine that later on can be targeted using gene editing methods such as CRISPR-Cas9. Unlike transgenic crops, the final product of gene editing can be cleared of any foreign DNA segments. Instead of relying on transgenic insertions, gene editing may knock out or replace targeted native genes in the genome of the crop to give rise to desirable traits. The United States Department of Agriculture (USDA) has allowed gene edited crops to be labeled as non-GMO, which will make gene edited crops significantly less controversial than transgenic crops [39]. A recent study by Shew et al. showed that gene edited crops were preferred over GMO crops in multiple countries [40]. Thus, by studying the underlying GRN involved in lysine regulation in rice, we can identify potential targets for gene editing.

LKR and SDH are known regulators of lysine in the catabolic pathway, and genetically intervening them have been proven to prevent lysine degradation [41]. Therefore, in this paper, we focus on identifying lysine regulators in the biosynthesis pathway. Overexpressing the regulators in the biosynthesis pathway through gene editing techniques such as CRISPR-Cas9 has the potential to increase the free lysine content in rice. In Figure 2, we derive the GRN of the lysine biosynthesis pathway in rice (Oryza sativa) from the KEGG pathways database [42]. Each rectangular box in Figure 2 represents a gene in the lysine biosynthesis pathway. The gene names are annotated according to their respective MSU IDs (LOC_Os\#\#g\#\#\#\#) [43]. In addition to the MSU IDs, the boxes contain alphabets in red font within parenthesis. These alphabets are used as an alias for genes in the later sections of the paper. Genes I-N have been given names in the literature and these names have been mentioned in the boxes alongside their MSU IDs, e.g., gene K (LOC_Os03g09910) is also known as ALD1. The genetic interactions converge at LYSA (LOC_Os02g24354 or gene $\mathrm{N}$ ), which positively regulates the amino acid lysine (L-Lysine, where the $\alpha$ carbon is in the $\mathrm{S}$ configuration ). This makes LYSA (gene N) a reporter gene of lysine. Thus, our objective is to identify genes that will upregulate $L Y S A$.

To identify the LYSA regulators, we will model the GRN of the lysine biosynthesis pathway using Bayesian networks (BN). We will then use publicly available data to infer the BN model's parameters. The model can then be used to identify the genes that upregulate LYSA. This modeling pipeline is similar to our previous work where we identified regulators of drought response in Arabidopsis [44,45]. We identify the LYSA regulators under normal and saline stress $(\mathrm{NaCl})$ conditions. Soil salinity is one of the significant environmental constraints on the crop life cycle. Nearly 5\% (77 million hectares) of the global arable land has excess salinity [46]. Due to various factors such as climate change and irrigation malpractices, the soil salinity is predicted to increase by 16.2 million hectares by $2050[47,48]$. Among abiotic stresses, soil salinity is the second largest cause of crop loss in rice after drought $[49,50]$. Saline stress primarily affects rice during its seedling, early vegetative, and reproductive stages $[49,51]$. We have extensively studied and identified regulators of drought response in our previous work [44,45]; in our current study however, we focus on saline stress in rice. We are specifically interested in observing if the LYSA regulators change under saline stress. Stewart et al. showed that saline stress leads to the accumulation of aspartic acid (aspartate), which is the first element in the lysine biosynthesis pathway [52]. Furthermore, it has been reported that under stressed conditions, aspartic acid catabolizes into asparagines, threonine, lysine, isoleucine, and methionine [53]. Studies involving maize and wheat showed increased lysine content under saline stress; however, the precise effect of saline stress on the lysine content in rice remains to be explored [54,55]. 


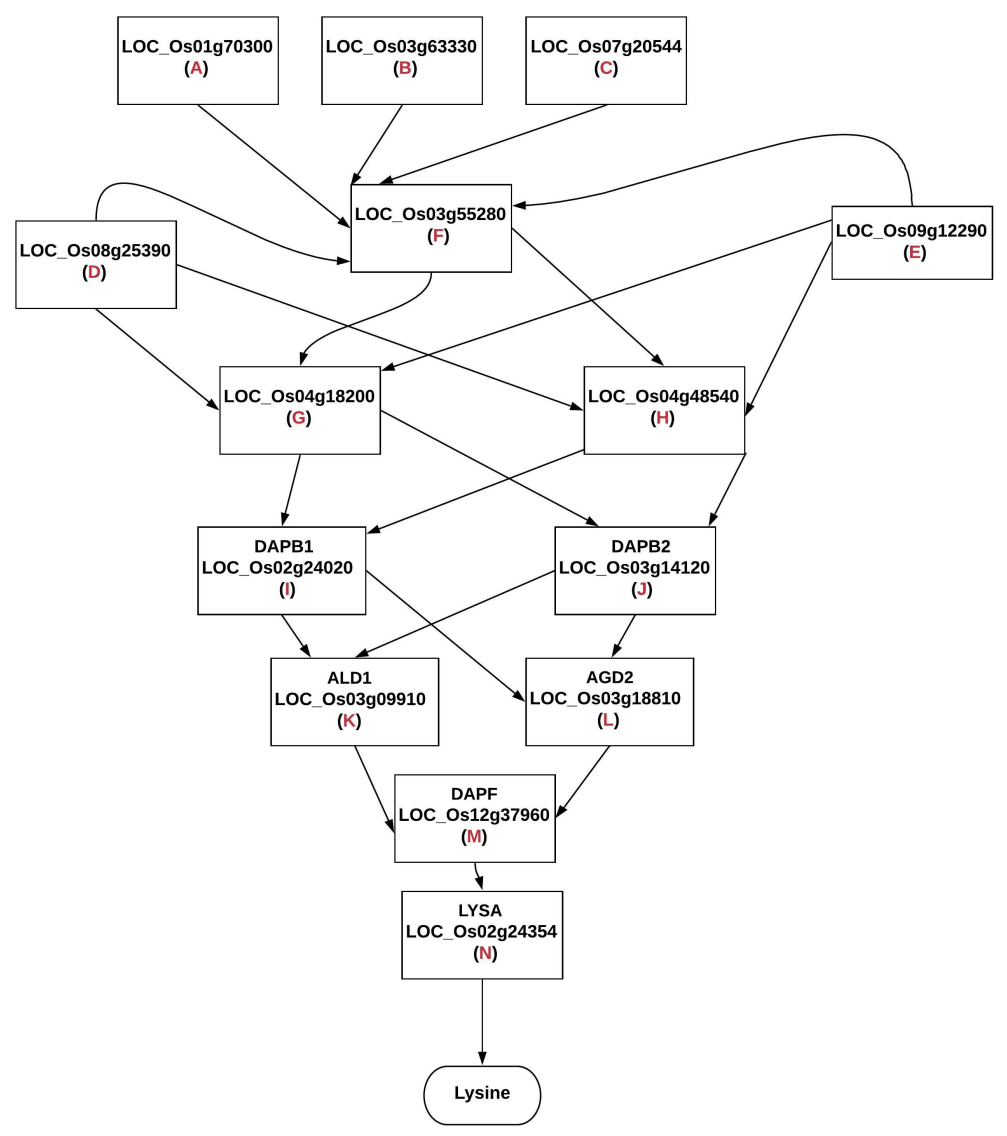

Figure 2. Gene regulatory network for lysine biosynthesis pathway in rice. The gene names are presented according to their MSU IDs. The alphabets in red font are aliases for the respective genes, e.g., LOC_Os01g70300 is referred to as gene A. Genes I-N have been given names in the literature; these have been mentioned in the figure alongside their respective MSU IDs.

\section{Materials and Methods}

GRNs describe the complex interactions taking place between regulators and their target genes. Typically, regulators consist of transcription factors (TFs), genes, RNA binding proteins, and regulator RNAs that can control the gene expression of the target genes [56-58]. GRNs govern the decision-making process in response to endogenous and external stimuli; thus, understanding their behavior at the genomic level can give us critical insights into achieving desirable phenotypical traits like increased lysine content $[59,60]$. GRNs have been modeled extensively in the past for a wide range of applications such as discovering novel biological relationships, studying complex diseases, drug design, and developing pathogen-resistant crops [61-65]. Common modeling techniques include differential equations, linear models, Boolean networks, probabilistic Boolean networks, Bayesian networks, and small molecule level models [66-70]. Each technique has its set of advantages and limitations. Therefore, we must consider the nature of the interactions in the GRN and the overall domain of the study while selecting a modeling method. In this paper, we are interested in modeling the lysine biosynthesis pathway in rice under normal (unstressed) and saline stress conditions. The interactions taking place in the pathway are sparse, multivariate, and stochastic in nature. Furthermore, with the advent of high-throughput technologies, publicly available genomic data have become easily accessible [71]. Due to these factors, we will model the lysine biosynthesis pathway using Bayesian networks (BNs). BNs provide a stochastic framework and allow integration of pathway knowledge and data. 


\subsection{Bayesian Network Modeling}

BNs are a class of probabilistic graphical models (PGM) that integrate probability and graph theory to represent stochastic and causal relationships among variables in a system [72,73]. BNs consist of two main components (i) a directed acyclic graph (DAG) and (ii) local probability distributions (LPD) or the network parameters [74]. The DAG is a map that describes the causal relationships among the system variables, also known as nodes. DAGs specify the dependencies among the nodes and explain the flow of cause and effect in the overall network. The DAG can be derived from the literature or estimated from data using structure learning algorithms [75]. Associated with each node in the DAG is a local probability distribution (LPD) that describes the stochastic nature of interaction among the connected nodes [73]. The LPDs and the DAGs together describe the factorization of the joint probability distribution of all the nodes in terms of their LPDs. In order to formalize this notion, consider a BN with $N$ nodes such that it has a DAG structure $\mathcal{G}(X, E)$, where $X_{i}$ represents the $i$ th node in the set of nodes $X$ and $E$ represents the set of casual edges between the nodes. Now, suppose the LPD for each node $X_{i}$ is given by $P\left(X_{i} \mid \mathrm{P}_{a}\left(X_{i}\right)\right)$, where $P_{a}\left(X_{i}\right)$ is the set of parent nodes of $X_{i}$. Then, by the local Markov independence assumption, each node, given its parent nodes, is independent of its nondescendant nodes. We can then factorize the joint probability of all the nodes in $X$ as:

$$
P\left(X=\left\{X_{1}, X_{2}, \ldots, X_{i}, \ldots, X_{N}\right\}\right)=\prod_{i=1}^{N} P\left(X_{i} \mid P_{a}\left(X_{i}\right)\right)
$$

To model the lysine biosynthesis pathway using BN, we construct a DAG from the Kegg pathway that we discussed in Figure 2. Learning the DAG from data is an NPhard problem and often requires selecting a graph structure from a candidate of possible DAGs $[76,77]$. This is a computationally expensive task, and the size of publicly available genomic data sets is not sufficiently large to produce a reliable DAG. Therefore, we use pathway information (see Figure 2) to construct the DAG for the lysine biosynthesis pathway in Figure 3. Every node (represented by circles) in the DAG represents a gene present in the lysine biosynthesis pathway. These genes are referenced by their aliases; for instance, gene $\mathrm{N}$ represents LYSA. The nodes are connected by arrows that represent actual biological relationships as described in the pathway. We assume that genes in the network can be active, dormant, or inhibited. Thus, we model each node as a categorical random variable with three states 1 (active), 0 (dormant), and -1 (inhibited). Associated with each node is a rectangular box that describes the LPD (network parameter). For Node A, $\theta_{A}$ is a vector representing the marginal probability of gene A being active, dormant, or inhibited. Similarly, $\theta_{M \mid L, K}$ is a vector representing the conditional probability of gene $M$ being active, dormant, or inhibited given the states of its parents, gene $\mathrm{L}$ and gene $\mathrm{K}$. This completes our discussion of the DAG for the lysine biosynthesis pathway. In the next section, we will discuss how to estimate the LPDs. Once all the LPDs have been calculated, the Bayesian network model is complete and can be used to perform gene intervention simulation under normal and saline stress conditions. These simulations will help us gain insight into the effect of intervening at the various genes. Genes that upregulate LYSA (gene N) will be considered ideal targets for genetic intervention. Interventions in the GRN can be carried out using gene editing methods such as CRISPR-Cas9 [60]. A simple example BN with its LPDs is shown in Section 2.3 for the purpose of demonstrating inference in BN. This example might be useful in developing a better understanding of the DAG structure and the LPDs. 


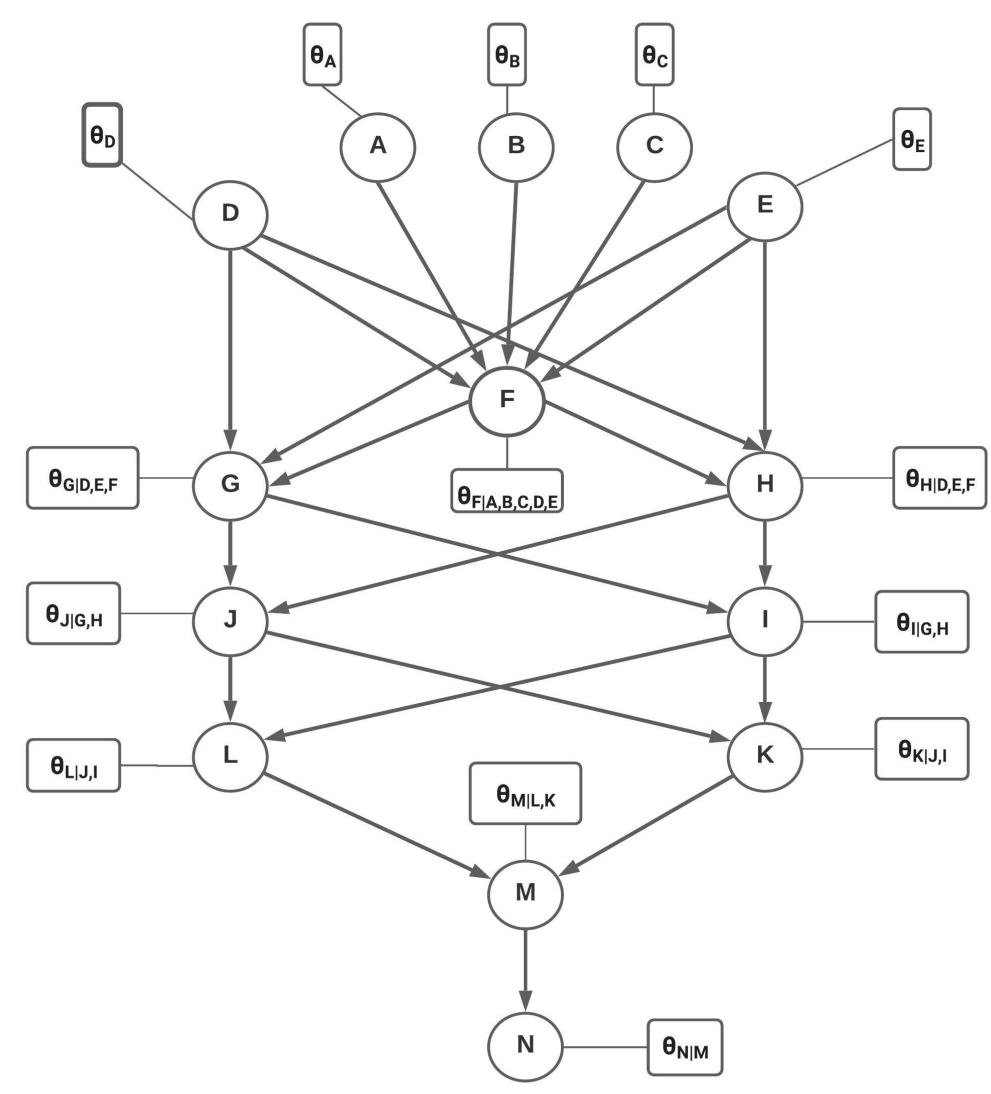

Figure 3. Directed acyclic graph (DAG) of the lysine biosynthesis pathway. Each node (circle) represents a gene in the pathway. The rectangular boxes represent the local probability distributions of the respective nodes. Each node is modeled as a categorical random variable with the following states: active (1), dormant (0), and inhibited (-1).

\subsection{Parameter Estimation}

Several methods can be employed to estimate the LPDs (network parameters) in a BN. Frequentist approaches such as maximum likelihood estimation (MLE) are common when estimating the LPDs in a BN [78]. However, we will use a Bayesian approach to estimate the LPDs for the DAG constructed in the previous section. This is because the sizes of publicly available data sets are not sufficiently large to be reliably used by data-driven frequentist approaches. Unlike frequentist approaches, Bayesian estimation produces a posterior probability distribution for the LPDs based on data and prior knowledge [79]. The point estimate for the LPDs can be obtained by approximating the posterior distributions by their expected value or mode [80]. The Bayesian estimation process is based on Bayes's rule where the posterior distribution of a random variable $X$, for a data set $\mathcal{D}$, is given by:

$$
P(X \mid D)=\frac{P(\mathcal{D} \mid X) P(X)}{P(\mathcal{D})}
$$

where $P(X)$ is the prior distribution of $X$.

We will now use this approach to derive the general expression for estimating the LPDs for a BN where the nodes are modeled as categorical random variables. We can then extend our findings to the DAG in Figure 3.

Consider a BN with a DAG denoted by $\mathcal{G}$ containing $N(N$ is a natural number) nodes. Each node $X_{i}$ in $\mathcal{G}$ is modeled as a categorical random variable with the following states: active (1), dormant (0), and inhibited (0). Thus, for any node $X_{i}$ in $\mathcal{G}, X_{i} \in \mathbf{S}=\{1,0,-1\}$, so if $X_{i}=0$, it implies that the node $X_{i}$ is dormant. Let the probability with which $X_{i}$ assumes 
any of the states in set $\mathbf{S}$ be given by the probability vector $\theta_{X_{i}}$. Then, $\theta_{X_{i}}$ is of the form $\left[\theta_{X_{i}=1}, \theta_{X_{i}=0}, \theta_{X_{i}=-1}\right]^{T}$, where $\theta_{X_{i}=s}$ represents the probability of $X_{i}=\mathrm{s}$ for $\mathrm{s} \in \mathbf{S}$ and $\Sigma_{s} \theta_{X_{i}=s}$ $=1$. Now, suppose we have a data set $\mathcal{D}$ that contains $n$ ( $n$ is natural number) independent and identically distributed (i.i.d.) observations for each of the $N$ nodes in $\mathcal{G}$. For a node $X_{i}$ in $\mathcal{G}$, let $\mathrm{M}_{X_{i}}\left[\mathbf{S}=\mathrm{s}\right.$ ] represent the frequency of $X_{i}=\mathrm{s}$ in $\mathcal{D}\left(\Sigma_{s} \mathrm{M}_{X_{i}}[\mathrm{~s}]=\mathrm{n}\right)$. Then, the likelihood under the data set $\mathcal{D}$ can be modeled as:

$$
\begin{array}{r}
P\left(X_{i} \mid P_{a}\left(X_{i}\right), \theta_{X_{i}}\right) \sim \text { Multinomial }\left(\theta_{X_{i}}, n\right) \\
\text { Multinomial }\left(\theta_{X_{i}}, n\right)=n ! \prod_{s \in \mathbf{S}} \frac{\theta_{X_{i}}^{M_{X_{i}}[s]}}{M_{X_{i}}[s] !}
\end{array}
$$

The Bayesian estimation process requires selecting a prior distribution. Prior distributions can be selected based on domain knowledge; however, in the absence of domain knowledge, there are no fixed methods to choose a prior distribution. The subjective selection of the prior distribution is often cited as a drawback of the Bayesian estimation process, as different priors lead to different results for the posterior distribution [81]. We set the prior distribution on $\theta_{X_{i}}$ for each node $X_{i} \in \mathcal{G}$ to follow a Dirichlet distribution. A Dirichlet prior distribution under a multinomial likelihood causes the posterior distribution to also follow a Dirichlet distribution. This is because the multinomial and Dirichlet distributions belong to conjugate families of distributions $[82,83]$. Therefore, we have the following formulation for the posterior distribution on $\theta_{X_{i}}$ :

$$
\begin{gathered}
\theta_{X_{i}} \sim \operatorname{Dirichlet}(\boldsymbol{\alpha}) \\
\boldsymbol{\alpha}=\left[\alpha_{s=1}, \alpha_{s=0}, \alpha_{s=-1}\right] \\
\operatorname{Dirichlet}\left(\theta_{X_{i}} ; \boldsymbol{\alpha}\right)=\frac{1}{\beta(\boldsymbol{\alpha})} \prod_{s \in \mathbf{S}}\left[\theta_{X_{i}=s}\right]^{\alpha_{s}-1}
\end{gathered}
$$

where $\beta(\boldsymbol{\alpha})$ is the Multivariate Beta function

$$
P\left(\theta_{X_{i}} \mid X_{i}\right)=\operatorname{Dirichlet}\left(\boldsymbol{\alpha}^{\prime}\right)
$$

and

$$
\begin{gathered}
\boldsymbol{\alpha}^{\prime}=\left[\alpha_{s=1}+M_{X_{i}}[s=1], \alpha_{s=0}+M_{X_{i}}[s=0], \alpha_{s=-1}+M_{X_{i}}[s=-1]\right] \\
\alpha^{\prime}=\left[\alpha_{s=1}^{\prime}, \alpha_{s=0}^{\prime}, \alpha_{s=-1}^{\prime}\right]
\end{gathered}
$$

In our study, we specifically set the prior distribution on each node $X_{i}$ to be Dirichlet $\left(\alpha_{s=1}=1, \alpha_{s=0}=1, \alpha_{s=-1}=1\right)$, which corresponds to uniform distribution over the open standard 2-simplex and is a noninformative prior distribution [84,85]. This is an appropriate choice for the prior distribution in our study, as we do not have prior knowledge regarding the distribution of each node in the BN. Furthermore, this assumption on the prior distribution of the nodes allows us to obtain a closed form solution for the posterior distribution. Selecting a different prior distribution will often lead to nonclosed form solution for the posterior distribtion and calculating the probability of data $(P(\mathcal{D}))$ can be computationally expensive [86]. The formulation in Equation (7) represents the posterior distribution of the node parameter $\theta_{X_{i}}$. We approximate $\theta_{X_{i}}$ by its expected value in order 
to obtain a point estimate for the LPDs in the BN. The expectation of a Dirichlet distribution is given by [87]:

$$
\theta_{X_{i}}=\left[\begin{array}{c}
\theta_{X_{i}=1} \\
\theta_{X_{i}=0} \\
\theta_{X_{i}=-1}
\end{array}\right] \approx E\left[\theta_{X_{i}} \mid X_{i}\right]=\left[\begin{array}{c}
\alpha_{s=1}^{\prime} \\
\sum \mathbf{s} \alpha_{s}^{\prime} \\
\alpha_{s=0}^{\prime} \\
\sum \mathbf{s} \alpha_{s}^{\prime} \\
\frac{\alpha_{s=-1}^{\prime}}{\sum \mathbf{s} \alpha_{s}^{\prime}}
\end{array}\right]
$$

Similarly, if we have a node $X_{i}$ with a parent node $Y_{i}=s(s \in \mathbf{S})$ under the same Dirichlet and multinomial framework, then the LPD associated with $\theta_{X_{i}} \mid Y_{i}$ can formulated as follows:

$$
\theta_{X_{i} \mid Y_{i}=s}=\left[\begin{array}{c}
\theta_{X_{i}=1 \mid Y_{i}=s} \\
\theta_{X_{i}=0 \mid Y_{i}=s} \\
\theta_{X_{i}=-1 \mid Y_{i}=s}
\end{array}\right] \approx E\left[\theta_{X_{i} \mid Y_{i}=s} \mid\left(X_{i} \mid Y_{i}=s\right)\right]=\left[\begin{array}{c}
\alpha_{s=1}+M_{X_{i} \mid Y_{i}}\left[X_{i}=1, Y_{i}=s\right] \\
\sum \mathbf{s} \alpha_{s}+M_{X_{i}} \mid Y_{i}\left[X_{i}=1, Y_{i}=s\right] \\
\alpha_{s=0}+M_{X_{i} \mid Y_{i}}\left[X_{i}=0, Y_{i}=s\right] \\
\sum \mathbf{s} \alpha_{s}+M_{X_{i} \mid Y_{i}}\left[X_{i}=0, Y_{i}=s\right] \\
\alpha_{s=-1}+M_{X_{i} \mid Y_{i}}\left[X_{i}=-1, Y_{i}=s\right] \\
\sum \mathbf{s} \alpha_{s}+M_{X_{i} \mid Y_{i}}\left[X_{i}=-1, Y_{i}=s\right]
\end{array}\right]
$$

In Equation (9), $M_{X_{i} \mid Y_{i}}\left[X_{i}=1, Y_{i}=\mathrm{s}\right]$ represents the frequencies when $X_{i}=1$ and $Y_{i}=s$ simultaneously in the data set $\mathcal{D}$. Similarly, $M_{X_{i} \mid Y_{i}}\left[X_{i}=0, Y_{i}=\mathrm{s}\right]$ is the frequency of data points in $\mathcal{D}$ when $X_{i}=0$ and $Y_{i}=$ s simultaneously, and so on for $X_{i}=-1$. Once the node parameters are estimated, gene intervention simulations can be carried out using inference in the BN. Inference computes the effect of intervening at each node on the reporter gene LYSA (gene N).

\subsection{Gene Intervention Simulations}

BNs represent the cause and effect relationship among the nodes of the system being modeled. Inference quantifies the cause and effect relationship by allowing us to compute conditional probability queries. Then, for a node of interest $X$, also known as the query node and an intervention (or evidence) node $\mathrm{E}$ in the $\mathrm{BN}$, we can compute the conditional probability $P(X \mid E)$ using inference algorithms. This implies that we can calculate its effect on node $X$ if we instantiate (fix) node E. Inference algorithms use the network parameters and structural dependencies to compute the required conditional probabilities. To further elucidate this notion, consider the BN shown in Figure 4. Let each node of the BN be a binary random variable with states 0 and 1 . Suppose we have estimated the LPDs $P(A), P(B \mid A), P(C \mid A)$, and $P(D \mid B, C)$; then, we can use inference in this $\mathrm{BN}$ to answer conditional probability queries such as $P(D=1 \mid A=1)$.

We compute $P(D=1 \mid A=1)$ as follows:

$$
\begin{gathered}
P(D=1 \mid A=1)=\frac{P(D=1, A=1)}{P(A=1)} \\
=\frac{\sum_{B} \sum_{C} P(A=1, B, C, D=1)}{P(A=1)}
\end{gathered}
$$

Using the properties of the BN, all nodes are independent of any nondescendant nodes

$$
\begin{aligned}
P(D=1 \mid A & =1)=\frac{\sum_{B} \sum_{C} P(A=1) P(B \mid A) P(C \mid A=1) P(D=1 \mid B, C)}{P(A=1)} \\
& =\sum_{B} \sum_{C} P(B \mid A=1) P(C \mid A=1) P(D=1 \mid B, C)
\end{aligned}
$$

We can use the LPDs to calculate the exact probability $P(D=1 \mid A=1)$. 
Inference techniques such as the one applied in the BN in Figure 4 are classified as "exact" because they compute the true values for the conditional probability query. However, exact inference in BNs has been shown to be NP-hard [88,89]. While there exist efficient algorithms for exact inference, they are often limited to simpler DAG structures [88]. For example, Pearl's message-passing algorithm works efficiently for singly connected DAG structures [90]. Therefore, for larger DAGs, exact inference is not ideal as the computational cost of calculating the conditional probabilities can be expensive. In such cases, we employ approximate inference algorithms, which produce estimates of the exact conditional probabilities [91]. Approximate inference can include wide-ranging techniques such as model simplification methods, loopy belief propagation methods, search-based methods, utility-based methods, and stochastic simulation methods [92]. In this paper, we implement a stochastic simulation-based inference technique called likelihood weighting (LW) to estimate the conditional probability queries in the BN model for the lysine biosynthesis pathway. Stochastic simulation techniques estimate the conditional probabilities by drawing samples from the LPDs. These estimates typically converge to the true conditional probabilities as the number of samples drawn increases. LW can efficiently handle inference of large multiply connected BNs and is based on forward sampling [92,93]. Since our BN model is multiply connected and we are only interested in estimating $P(N=1 \mid E \in\{A, B, C, \ldots, M\})$, i.e., the probability of upregulating $L Y S A$ (gene $\mathrm{N}$ ), while conditioning on other genes (evidence or intervention nodes), LW turns out be a suitable method for performing inference.

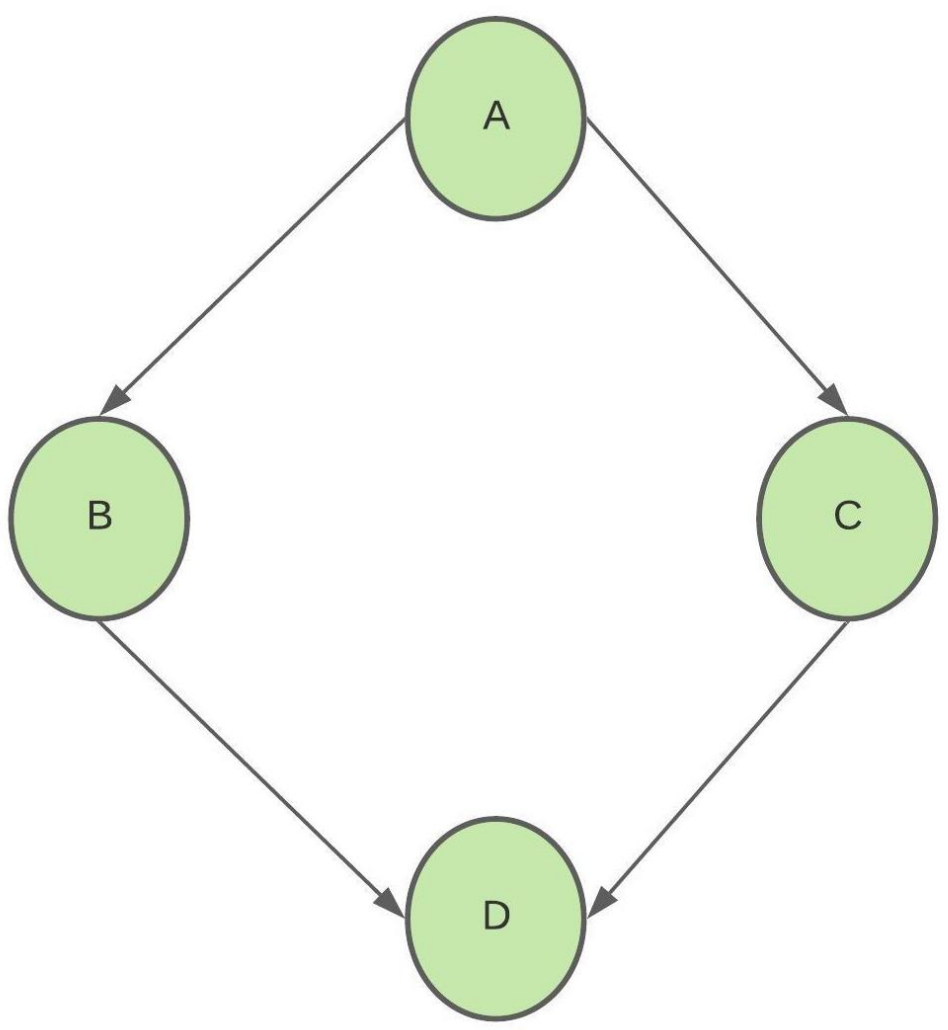

Figure 4. Example BN with binary nodes.

The LW algorithm estimates the conditional probability, $P(X=x \mid E=e)$ for a query node $X$ and an evidence node $E$, by generating samples from a BN model. We fix the sample size $(m)$ and a topological ordering at the start of the algorithm. The algorithm iterates through a sample generation process $m$ times, and then computes the conditional probability from the generated samples. During the sample generation process, the algorithm generates values for the nonevidence nodes only; it sets the value of the evidence node to its observed ( $e$, in this case) value. The node values for each sample are 
generated in the established topological ordering. Each sample is assigned a weight of 1 at the start of the sample generation process. The weight is updated only when an evidence node is encountered while traversing the topological ordering. When this happens, the sample's weight is updated by multiplying the current weight with the likelihood of the evidence node conditioned on the state of its parent nodes. The likelihood is given by the probability $P\left(E=e \mid P_{a}(E)\right)$. The process is repeated until $m$ samples are generated. Following this step, conditional probability is estimated by dividing the sum of the weights of the samples where $X=x$ by the sum of all the sample's weights. The pseudocode for the LW algorithm by Stuart Russell and Peter Norvig is presented in Algorithm 1 [94].

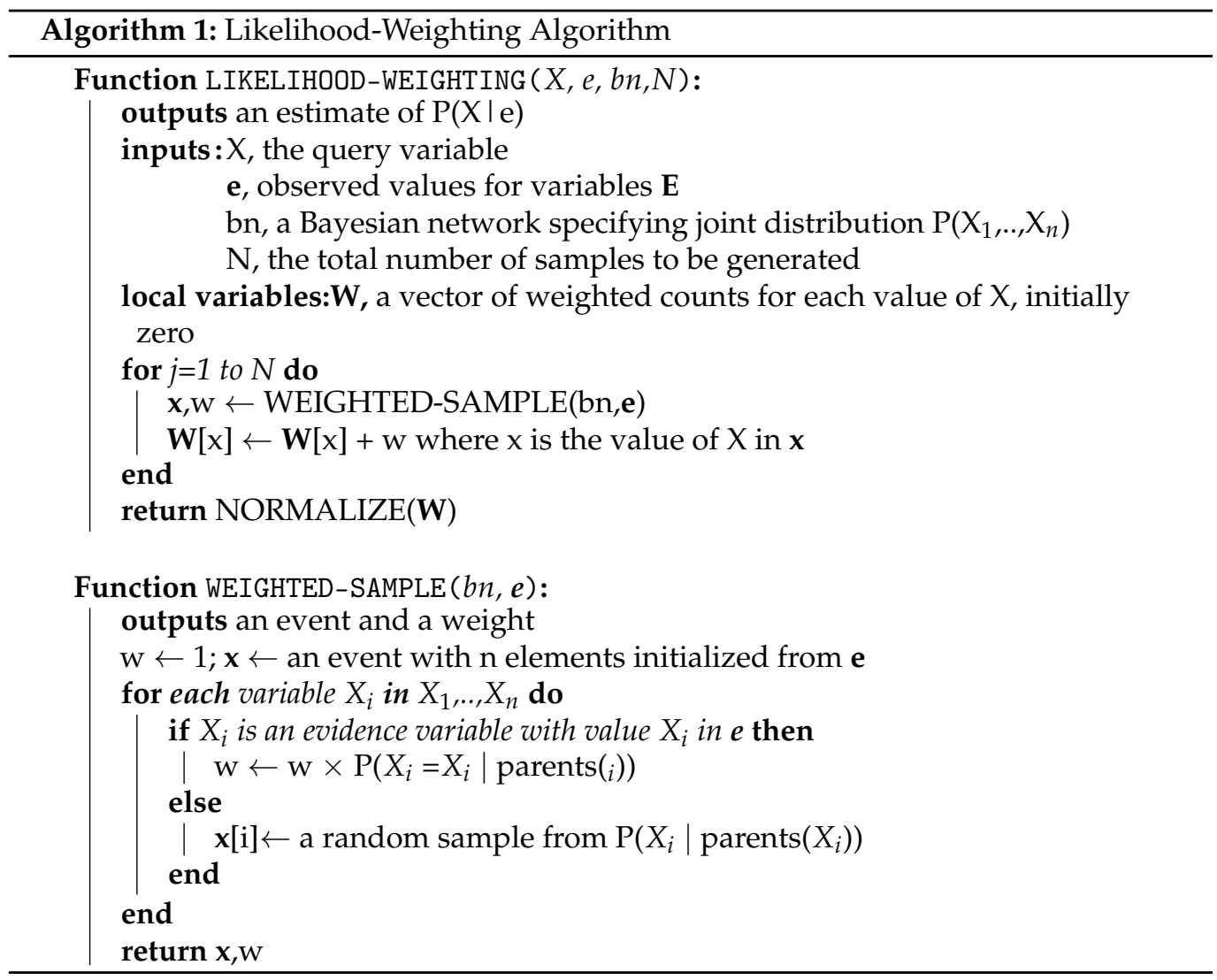

\subsection{Data Set}

To estimate the LPDs in the BN model, we use the data set GSE98455, which is publicly available from the NCBI GEO database [95-97]. This data set was selected because it contains RNA-Seq counts for rice seedlings under saline stress and normal (unstressed or control) conditions and had the highest number of samples (data points) per gene available among publicly available data sets. The entire data set contained 57,846 rows (genes) and 368 columns (control and saline stress). Since our BN model contains nodes modeled as categorical variables, the RNA-Seq data had to be preprocessed. The data preprocessing steps are outlined as follows:

1. The entire data set was normalized using the ratio of medians methods.

2. We selected the data for the genes $\mathrm{A}-\mathrm{N}$, as these were the genes in the BN model. We identified the data for each of the genes by mapping their data set IDs to their respective MSU IDs. This reduced our data set to a size of 14 rows (Gene A-N) and 368 columns.

3. We further segregated the normalized data set based on saline stress and normal conditions. Since the number of columns for saline stress and normal conditions were the same, each of the resulting data set had 14 rows and 184 columns. 
4. We ran $K$-means clustering separately on both the saline stress and normal conditions data set to convert them from normalized to categorical values. The clustering process categorized the data in both the data sets into the following values 1 (active), 0 (dormant), and -1 (inhibited). The low expression values were categorized to the value of -1 , the high expression values were categorized to the value of 1 , and the remaining expression values in the middle were categorized to a value of 0 .

Once the categorical values were obtained for both the treatment and control data sets, the LPDs were estimated under each case using the Bayesian approach described in the Parameter Estimation section. We then ran LW to simulate gene intervention. The ratio of medians methods used for normalization is described in the DESeq2 data processing protocols by Love et al. [98]. DESeq2 is one of the most commonly used RNA-Seq data processing protocols and is easily accessible in the $\mathrm{R}$ programming language as a package (DESeq2) [99-102]. The file for mapping data set IDs to MSU IDs was provided to us by the authors of the data set GSE98455. We have highlighted their contribution in the acknowledgment section. A visual representation of the data processing pipeline is presented in Figure 5. Figures 6 and 7 show the discretized categorical data for each node in the BN under normal and saline stress conditions, respectively.

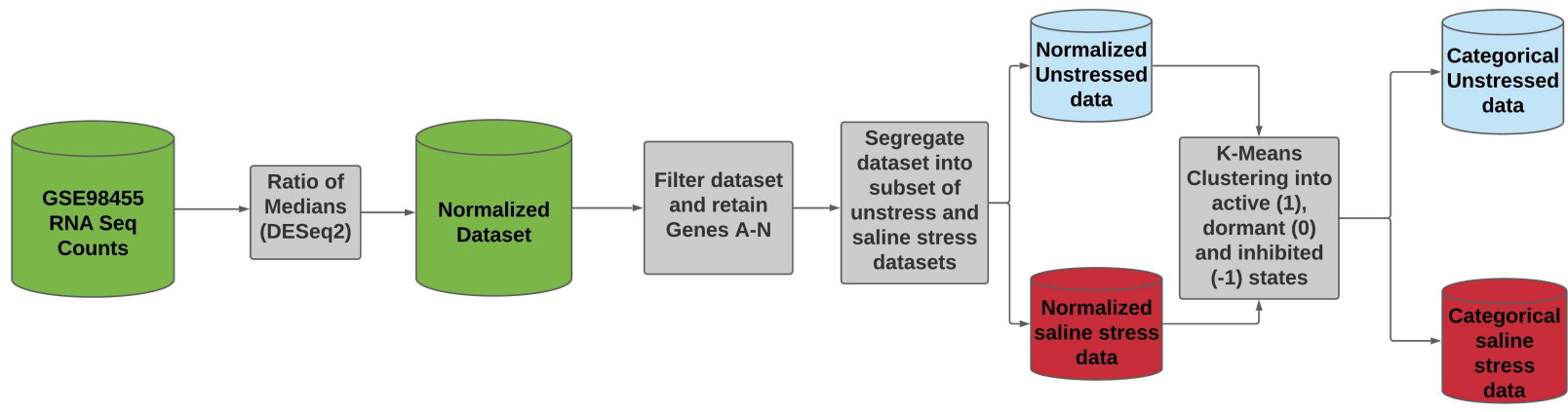

Figure 5. Data processing pipeline for RNA-Seq data set GSE98455.

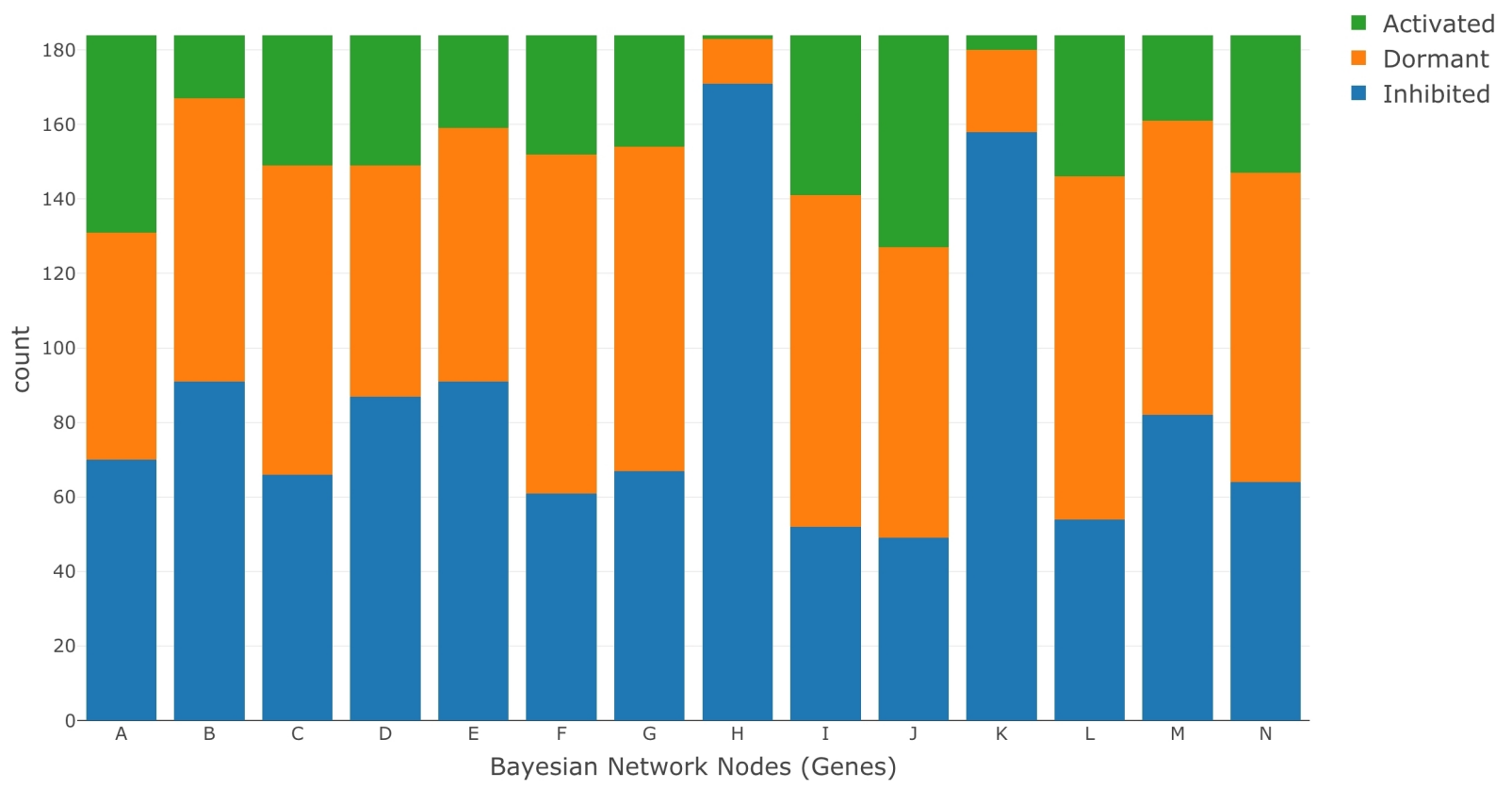

Figure 6. Discretized RNA-Seq data under normal conditions. 


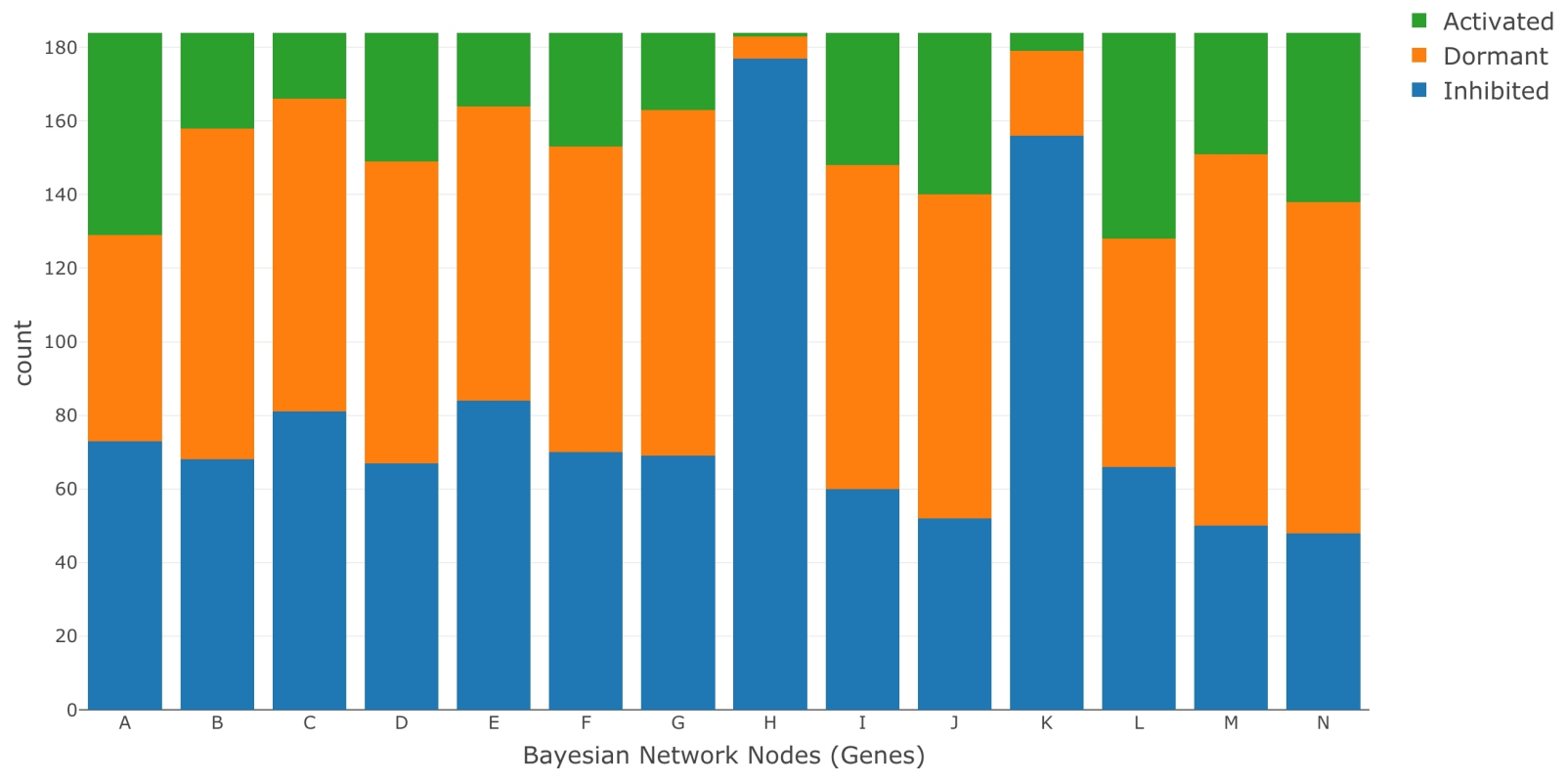

Figure 7. Discretized RNA-Seq data under saline stress conditions.

\section{Results}

The LPDs estimated from the RNA-Seq data set were used to simulate gene intervention in the $\mathrm{BN}$. When intervening at a gene, the node representing that gene in the $\mathrm{BN}$ was instantiated to a status of active (1), dormant (0), or inhibited (-1). We applied the LW algorithm with a large sample size of 600,000 to compute the probability $P(N=1 \mid$ gene intervention) and ensure convergence of the probabilities being estimated. Gene $\mathrm{N}$ (LYSA) is set as the query node because it is the reporter gene for lysine production; thus, upregulating gene $\mathrm{N}$ (LYSA) may lead to increased lysine production. We perform intervention at genes A-M one at a time and then in combinations of two (pairs) at a time. These gene intervention strategies were applied under both normal and saline stress conditions. In order to measure the causal effect of intervention, we subtract the marginal probability $P(N=1)$ from $P(N=1 \mid$ gene intervention), for all the possible gene intervention strategies. This difference is defined as the score metric and is used to compare the effectiveness of each gene intervention strategy. The data processing and probability computation pipeline was written in the $\mathrm{R}$ programming language, and the Bnlearn package was used to perform LW [103-105]. So,

$$
\text { score }=P(N=1 \mid \text { gene intervention })-P(N=1) .
$$

Since there are many possible combinations under single and pairwise gene interventions, we only include the top five intervention strategies with the highest scores in Figure 8 and Tables 1 and 2. The proteins encoded by each of the genes in these intervention strategies are summarized in Table 3. In Figure 8a,b, we present the scores for single node intervention under normal and saline stress conditions. 

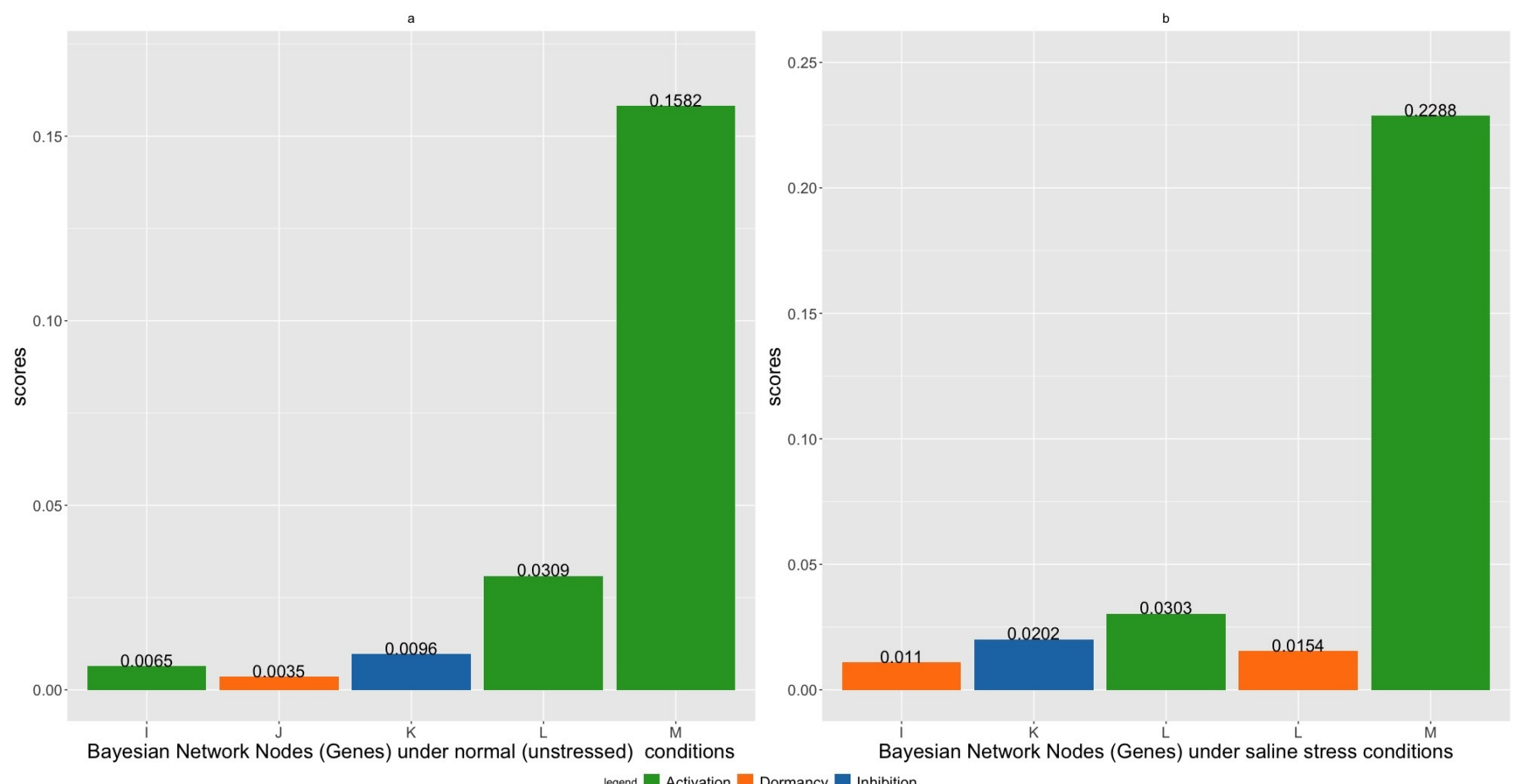

Figure 8. Single node intervention under (a) normal and (b) saline stress conditions.

It is clear from Figure $8 \mathrm{a}, \mathrm{b}$ that activating gene $\mathrm{M}(D A P F)$ has the maximum score. This implies that, under both normal and saline stress conditions, genetically activating gene $\mathrm{M}$ $(D A P F)$ has the best chance for upregulating the reporter gene $\mathrm{N}(L Y S A)$. We also notice that gene $\mathrm{L}(A G D 2)$ is also fairly active in its role in upregulating gene $\mathrm{N}(L Y S A)$. Activating gene $\mathrm{L}(A G D 2)$ achieves the second largest score under normal conditions. Under saline stress conditions, activating gene L (AGD2) or keeping it dormant also ranks among the top five gene intervention strategies. Inhibiting gene $\mathrm{K}(A L D 1)$ achieves the third and second highest scores under normal and saline stress conditions. Additionally, we also observe that midstream genes such as gene I (DAPB1) and gene $\mathrm{J}(D A P B 2)$ also play an active role in upregulating gene $\mathrm{N}(L Y S A)$. However, activating gene $\mathrm{M}(D A P F)$ has a significantly higher score under both conditions; thus, gene $\mathrm{M}(D A P F)$ servers as an ideal candidate for gene intervention.

Table 1. Top five pairwise intervention strategies under normal conditions.

\begin{tabular}{cccccc}
\hline Index & Gene Name/Alias & Intervention & Gene Name/Alias & Intervention & Score \\
\hline 1 & $A L D 1($ Gene K) & Active & $D A P F($ Gene M) & Active & 0.1657 \\
2 & $A L D 1($ Gene K) & Dormant & $D A P F($ Gene M) & Active & 0.1653 \\
3 & $A G D 2($ Gene L) & Inhibited & $D A P F($ Gene M) & Active & 0.1639 \\
4 & Gene A & Active & $D A P F($ Gene M) & Active & 0.1637 \\
5 & Gene C & Active & $D A P F($ Gene M) & Active & 0.1634 \\
\hline
\end{tabular}

Table 2. Top five pairwise intervention strategies under saline stress conditions.

\begin{tabular}{cccccc}
\hline Index & Gene Name/Alias & Intervention & Gene Name/Alias & Intervention & Score \\
\hline 1 & Gene F & Dormant & $D A P F($ Gene M) & Active & 0.2322 \\
2 & $A L D 1($ Gene K) & Dormant & $D A P F($ Gene M) & Active & 0.2321 \\
3 & Gene B & Inhibited & $D A P F($ Gene M) & Active & 0.2312 \\
4 & Gene E & Inhibited & $D A P F($ Gene M) & Active & 0.2306 \\
5 & Gene A & Dormant & $D A P F($ Gene M) & Active & 0.2305 \\
\hline
\end{tabular}


Tables 1 and 2 represent the five highest-scoring pairwise intervention strategies for normal and saline stress conditions. Each table contains gene names or alias along with their intervention strategies. The tables are arranged in descending order of the score. Under each condition, the score amongst different five highest-scoring strategies are almost similar with marginal differences. Under normal conditions in Table 1, we observe that activating both gene $\mathrm{K}(A L D 1)$ and gene $\mathrm{M}(D A P F)$ maximized the scores. While under saline stress, keeping gene F (LOC_Os03g55280) dormant and activating gene M (DAPF) achieved the highest score. This implies that under each of the conditions, the respective pairwise intervention strategy with highest scores maximize the likelihood of upregulating gene $\mathrm{N}(L Y S A)$. From Tables 1 and 2, it can also be seen that upstream genes such as genes $\mathrm{A}$, $\mathrm{B}, \mathrm{C}$, and $\mathrm{E}$ are also involved in the upregulation of gene $\mathrm{N}(L Y S A)$ and produce comparable scores to those produced by the regulation of downstream genes such as gene $\mathrm{K}(A L D 1)$ and gene $\mathrm{L}(A G D 2)$. Across both the conditions, we also observe that gene $\mathrm{M}(D A P F)$ is always upregulated, which serves to be a further indicator of the high regulatory effect of gene $\mathrm{M}$ (DAPF) on gene $\mathrm{N}$ (LYSA). We should note that these rankings in Tables 1 and 2 might vary slightly upon rerunning the simulations, as LW is based on a stochastic simulation process, which may cause minor variation in estimating the probabilities required for computing the score metric. However, this does not affect our overarching conclusion that DAPF is the most potent regulator of $L Y S A$, as it is present and upregulated in all the top five strategies under pairwise intervention. Furthermore, under single intervention, $D A P F$ scores significantly higher than rest of the genes.

Table 3. Protein encoded by intervention genes in Figure 8 and Tables 1 and 2.

\begin{tabular}{ccc}
\hline Gene Alias/Name & MSU IDs & Protein \\
\hline Gene A & LOC_Os01g70300 & Aspartokinase 3, chloroplast precursor, putative, expressed \\
Gene B & LOC_Os03g63330 & Aspartokinase, chloroplast precursor, putative, expressed \\
Gene C & LOC_Os07g20544 & Aspartokinase, chloroplast precursor, putative, expressed \\
Gene E & LOC_Os09g12290 & Bifunctional aspartokinase/homoserine dehydrogenase, chloroplast precursor, putative, expressed \\
Gene F & LOC_Os03g55280 & Semialdehyde dehydrogenase, NAD binding domain containing protein, putative, expressed \\
Gene I/DAPB1 & LOC_Os02g24020 & Dihydrodipicolinate reductase, putative, expressed \\
Gene J/DAPB2 & LOC_Os03g14120 & Dihydrodipicolinate reductase, putative, expressed \\
Gene K/ALD1 & LOC_Os03g09910 & Aminotransferase, classes I and II, domain containing protein, expressed \\
Gene L/AGD2 & LOC_Os03g18810 & Aminotransferase, classes I and II, domain containing protein, expressed \\
Gene M/DAPF & LOC_Os12g37960 & Diaminopimelate epimerase, chloroplast precursor, putative, expressed \\
\hline
\end{tabular}

\section{Discussion}

In this paper, we studied the lysine biosynthesis pathway in rice to identify the genetic regulators of lysine content. Rice is a staple food source for $50 \%$ of the global population; with lysine being the first limiting essential amino acid in rice, it is vital to identify gene regulators that can boost lysine content. We modeled the lysine biosynthesis pathway in rice using BNs under normal and saline stress conditions to identify these regulators. We used BNs because they allow us to integrate domain knowledge in the form of pathway information with experimental data. We used publicly available RNA-Seq data to estimate the LPDs in the BN and run the gene intervention simulations. We intervened at the genes one at a time and then in pairwise combinations using the LW inference algorithm. We calculated a score metric to measure the efficacy of the gene intervention strategies.

Our analysis revealed that upregulating DAPF (gene $\mathrm{M}$ ) maximized the probability of the lysine reporter gene LYSA (gene N) being upregulated under both normal and saline stress conditions. When DAPF (gene $\mathrm{M}$ ) was upregulated, it not only achieved the highest score under single gene intervention but was also present in all the five highestscoring gene intervention strategies under pairwise intervention. This implies that DAPF (gene $\mathrm{M}$ ) is a positive regulator of LYSA (gene $\mathrm{N}$ ) and serves as an ideal candidate for genetic intervention. Gene editing can be used to target and upregulate DAPF (gene $\mathrm{M}$ ) in rice. Wet lab experiments involving $D A P F$ overexpressing rice can confirm if this intervention strategy upregulates LYSA and increases the overall lysine content. We further 
observed under single gene intervention that midstream genes such as DAPB1 (gene I) and DAPB2 (gene J) also played significant roles in upregulating LYSA (gene N). Under pairwise intervention, we found that upstream genes such as genes $A, B, C$, and $E$ were also involved in upregulating LYSA (gene $\mathrm{N}$ ).

Future steps in our study of lysine include confirming our finding in this paper by performing wet lab experiments. We would also like to improve our choice of the prior distribution on each node. In our current analysis, we used a noninformative prior distribution, as we did not have any knowledge regarding the prior distribution of the nodes in the BN. Using informative prior distributions may increase the computational costs, but it has the potential to improve our predictions of lysine regulators. Furthermore, we are also interested in studying how other essential amino acids such as threonine, methionine, and isoleucine in the larger aspartate pathway regulate lysine content. Threonine is known to downregulate the enzyme AK in the lysine biosynthesis pathway; thus, studying the multilevel regulation among the different amino acids in the aspartate pathway will help deepen our understanding of lysine production.

\section{Conclusions}

We modeled the lysine biosynthesis pathway in rice under normal and saline stress conditions to identify the regulators of lysine. Among the essential amino acids, lysine is present in the least quantity in rice; thus, increasing its content in rice will improve its nutritional value. Our analysis revealed that, under both the normal and saline stress conditions, upregulating DAPF is the best genetic intervention strategy for upregulating the lysine reporter gene LYSA. Applying gene intervention techniques such as CRISPRCas9-based gene editing to upregulate DAPF has the potential to increase the lysine content in rice.

Supplementary Materials: The following are available online at https:/ /www.mdpi.com/article/10 $.3390 /$ inventions6020037/s1.

Author Contributions: Conceptualization, E.M.S. and A.D.; methodology, A.L. and K.R; software, A.L.; validation, E.M.S. and K.R.; formal analysis, A.L. and A.D.; investigation, A.L. and A.D.; resources, A.D. and E.M.S.; data curation, A.L.; writing—original draft preparation, A.L.; writingreview and editing, A.L., A.D., K.R., and E.M.S.; visualization, A.L.; supervision, E.M.S. and A.D.; project administration, E.M.S. and A.D.; funding acquisition, E.M.S. and A.D. All authors have read and agreed to the published version of the manuscript.

Funding: This work was supported in part by the TEES-AgriLife Center for Bioinformatics and Genomic Systems Engineering (CBGSE) startup funds, the Texas A\&M X-Grant Program, and in part by the National Science Foundation under Grant ECCS-1609236 (to A.D.). The funding bodies did not play any role in the design of the study and collection, analysis, and interpretation of data and in writing the manuscript.

Institutional Review Board Statement: Not applicable.

Informed Consent Statement: Not applicable.

Data Availability Statement: The data sets used in this study are publicly available at the NCBI with the accession numbers of GSE98455. The subset of data extracted from the data set to support the conclusion of this article are included within the article. The $\mathrm{R}$ code containing the simulations are provided as supplemental files. The $\mathrm{R}$ code files are also publicly avaialble at the following Github repository: https://github.com/adilahiri/Lysine_Regulators (accessed on 16 May 2021).

Acknowledgments: We would like to recognize Chi Zhang, Associate Professor, School of Biological Sciences, University of Nebraska, Lincoln. He generously provided us with the gene annotation file required for analyzing the data set GSE98455.

Conflicts of Interest: The authors declare no conflict of interest.

\section{Abbreviations}


The following abbreviations are used in this manuscript:

$\begin{array}{ll}\text { LKR } & \text { Lysine ketoglutarate reductase } \\ \text { SDH } & \text { Saccharopine dehydrogenase } \\ \text { DHPS } & \text { Dihydrodipicolinate synthase } \\ \text { AK } & \text { Aspartate kinase } \\ \text { GRN } & \text { Gene regulatory network } \\ \text { GMO } & \text { Genetically modified organisms } \\ \text { MSU } & \text { Michigan State University } \\ \text { TF } & \text { Transcription factor } \\ \text { BN } & \text { Bayesian network } \\ \text { PGM } & \text { Probabilistic graphical model } \\ \text { LPD } & \text { Local probability distribution } \\ \text { i.i.d } & \text { Independent and identically distributed } \\ \text { LW } & \text { Likelihood weighting }\end{array}$

\section{References}

1. Alberts, B.; Bray, D.; Hopkin, K.; Johnson, A.; Lewis, J.; Raff, M.; Roberts, K.; Walter, P. Essential Cell Biology, 3rd ed.; Garland Science: New York, NY, USA, 2010; pp. 119-122.

2. Alberts, B.; Johnson, A.; Lewis, J.; Raff, M.; Roberts, K.; Walter, P. The shape and structure of protein. In Molecular Biology of the Cell, 4th ed.; Garland Science: New York, NY, USA, 2002.

3. Lopez, M.; Mohiuddin, S. Biochemistry, Essential Amino Acids; StatPearls Publishing: Treasure Island, FL, USA, 2020.

4. D'Mello, J.P.F. Amino acids as multifunctional molecules. In Amino Acids in Animal Nutrition, 2nd ed.; CABI Publishing: Cambridge, MA, USA, 2003; p. 2.

5. Hoffman, J.; Falvo, M. Protein-Which is Best? J. Sports Sci. Med. 2004, 3, 118.

6. Tien Lea, D.; Duc Chua, H.; Quynh Lea, N. Improving Nutritional Quality of Plant Proteins Through Genetic Engineering. Curr. Genom. 2016, 17, 220-229. [CrossRef]

7. Stencel, C.; Dobbins, C. Report Offers New Eating and Physical Activity Targets To Reduce Chronic Disease Risk. 2002 . Available online: https:/ / www.nationalacademies.org/news/2002/09/report-offers-new-eating-and-physical-activity-targetsto-reduce-chronic-disease-risk (accessed on 10 May 2021).

8. Zha, Y.; Qian, Q. Protein Nutrition and Malnutrition in CKD and ESRD. Nutrients 2017, 9, 208. [CrossRef]

9. National Research Council. Recommended Dietary Allowances, 10th ed.; National Academies Press: Washington, DC, USA, 1989; [CrossRef]

10. Titchenal, A.; Hara, S.; Arceo Caacbay, N.; Meinke-Lau, W.; Yang, Y.Y.; Ksinoa Fialkowski Revilla, M.; Draper, J.; Langfelder, G.; Gibby, C.; Nicole Chun, C.; et al. Human Nutrition, 2020th ed.; University of Hawaii at Manoa Food Science and Human Nutrition Program: Honolulu, HI, USA, 2020; pp. 395-402.

11. Henchion, M.; Hayes, M.; Mullen, A.; Fenelon, M.; Tiwari, B. Future Protein Supply and Demand: Strategies and Factors Influencing a Sustainable Equilibrium. Foods 2017, 6, 53. [CrossRef]

12. Vasileska, A.; Rechkoska, G. Global and Regional Food Consumption Patterns and Trends. Procedia Soc. Behav. Sci. 2012, 44, 363-369. [CrossRef]

13. Berrazaga, I.; Micard, V.; Gueugneau, M.; Walrand, S. The Role of the Anabolic Properties of Plant- versus Animal-Based Protein Sources in Supporting Muscle Mass Maintenance: A Critical Review. Nutrients 2019, 11, 1825. [CrossRef]

14. de Gavelle, E.; Huneau, J.F.; Bianchi, C.; Verger, E.; Mariotti, F. Protein Adequacy Is Primarily a Matter of Protein Quantity, Not Quality: Modeling an Increase in Plant:Animal Protein Ratio in French Adults. Nutrients 2017, 9, 1333. [CrossRef]

15. Abete, I.; Romaguera, D.; Vieira, A.R.; Lopez de Munain, A.; Norat, T. Association between total, processed, red and white meat consumption and all-cause, CVD and IHD mortality: A meta-analysis of cohort studies. Br. J. Nutr. 2014, 112, 762-775. [CrossRef]

16. Demeyer, D.; Mertens, B.; De Smet, S.; Ulens, M. Mechanisms Linking Colorectal Cancer to the Consumption of (Processed) Red Meat: A Review. Crit. Rev. Food Sci. Nutr. 2016, 56, 2747-2766. [CrossRef]

17. Malik, V.S.; Li, Y.; Tobias, D.K.; Pan, A.; Hu, F.B. Dietary Protein Intake and Risk of Type 2 Diabetes in US Men and Women. Am. J. Epidemiol. 2016, 183, 715-728. [CrossRef]

18. The Food and Agriculture Organization of the United Nations. Livestock Solutions for Climate Change; Technical Report; United Nations: New York, NY, USA, 2017.

19. United Nations. World Population Projected to Reach 9.8 Billion in 2050, and 11.2 Billion in 2100; United Nations: New York, NY, USA, 2017.

20. Day, L. Proteins from land plants-Potential resources for human nutrition and food security. Trends Food Sci. Technol. 2013, 32, 25-42. [CrossRef]

21. Rosegrant, M.W.; Leach, N.; Gerpacio, R.V. Alternative futures for world cereal and meat consumption. Proc. Nutr. Soc. 1999, 58, 219-234. [CrossRef] 
22. Millward, D.J.; Jackson, A.A. Protein/energy ratios of current diets in developed and developing countries compared with a safe protein/energy ratio: Implications for recommended protein and amino acid intakes. Public Health Nutr. 2004, 7, 387-405. [CrossRef]

23. Kusano, M.; Yang, Z.; Okazaki, Y.; Nakabayashi, R.; Fukushima, A.; Saito, K. Using Metabolomic Approaches to Explore Chemical Diversity in Rice. Mol. Plant 2015, 8, 58-67. [CrossRef]

24. Galili, G.; Amir, R. Fortifying plants with the essential amino acids lysine and methionine to improve nutritional quality. Plant Biotechnol. J. 2013, 11. [CrossRef]

25. Wang, W.; Galili, G. Transgenic high-lysine rice-a realistic solution to malnutrition? J. Exp. Bot. 2016, 67. [CrossRef]

26. Galili, G.; Karchi, H.; Shaul, O.; Perl, A.; Cahana, A.; Tzchori, I.B.T.; Zhu, X.Z.; Galili, S. Production of transgenic plants containing elevated levels of lysine and threonine. Biochem. Soc. Trans. 1994, 22. [CrossRef]

27. Grigg, D. The pattern of world protein consumption. Geoforum 1995, 26. [CrossRef]

28. Juliano, B.O. The Food and Agriculture Organization of the United Nations. World rice production compared to other cereals. In Rice in Human Nutrition; International Rice Research Institute of the United Nations: Rome, Italy, 1993.

29. Muthayya, S.; Sugimoto, J.D.; Montgomery, S.; Maberly, G.F. An overview of global rice production, supply, trade, and consumption. Ann. N. Y. Acad. Sci. 2014, 1324, 7-14. [CrossRef]

30. Kawakatsu, T.; Takaiwa, F. Differences in Transcriptional Regulatory Mechanisms Functioning for Free Lysine Content and Seed Storage Protein Accumulation in Rice Grain. Plant Cell Physiol. 2010, 51, 1964-1974. [CrossRef]

31. Frizzi, A.; Huang, S.; Gilbertson, L.A.; Armstrong, T.A.; Luethy, M.H.; Malvar, T.M. Modifying lysine biosynthesis and catabolism in corn with a single bifunctional expression/silencing transgene cassette. Plant Biotechnol. J. 2007. [CrossRef] [PubMed]

32. Arruda, P.; Barreto, P. Lysine Catabolism Through the Saccharopine Pathway: Enzymes and Intermediates Involved in Plant Responses to Abiotic and Biotic Stress. Front. Plant Sci. 2020, 11, 587. [CrossRef]

33. Long, X.; Liu, Q.; Chan, M.; Wang, Q.; Sun, S.S.M. Metabolic engineering and profiling of rice with increased lysine. Plant Biotechnol. J. 2013, 11, 490-501. [CrossRef]

34. Arruda, P.; Kemper, E.L.; Papes, F.; Leite, A. Regulation of lysine catabolism in higher plants. Trends Plant Sci. 2000, 5, 324-330. [CrossRef]

35. Yang, Q.Q.; Zhang, C.Q.; Chan, M.L.; Zhao, D.S.; Chen, J.Z.; Wang, Q.; Li, Q.F.; Yu, H.X.; Gu, M.H.; Sun, S.S.M.; et al. Biofortification of rice with the essential amino acid lysine: Molecular characterization, nutritional evaluation, and field performance. J. Exp. Bot. 2016, 67, 4285-4296. [CrossRef] [PubMed]

36. Zhu, X.; Galili, G. Increased Lysine Synthesis Coupled with a Knockout of Its Catabolism Synergistically Boosts Lysine Content and Also Transregulates the Metabolism of Other Amino Acids in Arabidopsis Seeds. Plant Cell 2003, 15, 845-853. [CrossRef] [PubMed]

37. Angelovici, R.; Fait, A.; Fernie, A.R.; Galili, G. A seed high-lysine trait is negatively associated with the TCA cycle and slows down Arabidopsis seed germination. New Phytol. 2011, 189, 148-159. [CrossRef]

38. Tzchori, I.B.T.; Perl, A.; Galili, G. Lysine and threonine metabolism are subject to complex patterns of regulation in Arabidopsis. Plant Mol. Biol. 1996, 32, 727-734. [CrossRef]

39. Rappe, M. CRISPR Plants: New Non-GMO Method to Edit Plants; North Carolina State University: Raleigh, NC, USA, 2020 .

40. Shew, A.M.; Nalley, L.L.; Snell, H.A.; Nayga, R.M.; Dixon, B.L. CRISPR versus GMOs: Public acceptance and valuation. Glob. Food Secur. 2018, 19, 71-80. [CrossRef]

41. Rastogi, K.; Ibarra, O.; Molina, M.; Faion-Molina, M.; Thomson, M.; Septiningsih, E.M. Using CRISPR/Cas9 Genome Editing to Increase Lysine Levels in Rice. In Proceedings of the ASA-CSSA-SSSA International Annual Meeting, San Antonio, TX, USA, 14 November 2019.

42. Kanehisa, M. KEGG: Kyoto Encyclopedia of Genes and Genomes. Nucleic Acids Res. 2000, 28, 27-30. [CrossRef] [PubMed]

43. Kawahara, Y.; de la Bastide, M.; Hamilton, J.P.; Kanamori, H.; McCombie, W.R.; Ouyang, S.; Schwartz, D.C.; Tanaka, T.; Wu, J.; Zhou, S.; et al. Improvement of the Oryza sativa Nipponbare reference genome using next generation sequence and optical map data. Rice 2013, 6. [CrossRef]

44. Lahiri, A.; Venkatasubramani, P.S.; Datta, A. Bayesian modeling of plant drought resistance pathway. BMC Plant Biol. 2019, 19. [CrossRef]

45. Lahiri, A.; Zhou, L.; He, P.; Datta, A. Detecting Drought Regulators using Stochastic Inference in Bayesian Networks. Manuscript submitted for publication. [CrossRef]

46. Sheng, M.; Tang, M.; Chen, H.; Yang, B.; Zhang, F.; Huang, Y. Influence of arbuscular mycorrhizae on photosynthesis and water status of maize plants under salt stress. Mycorrhiza 2008, 18, 287-296. [CrossRef] [PubMed]

47. Tisarum, R.; Theerawitaya, C.; Samphumphuang, T.; Polispitak, K.; Thongpoem, P.; Singh, H.P.; Cha-um, S. Alleviation of Salt Stress in Upland Rice (Oryza sativa L. ssp. indica cv. Leum Pua) Using Arbuscular Mycorrhizal Fungi Inoculation. Front. Plant Sci. 2020, 11, 348. [CrossRef]

48. Reddy, I.N.B.L.; Kim, B.K.; Yoon, I.S.; Kim, K.H.; Kwon, T.R. Salt Tolerance in Rice: Focus on Mechanisms and Approaches. Rice Sci. 2017, 24, 123-144. [CrossRef]

49. Kakar, N.; Jumaa, S.H.; Redoña, E.D.; Warburton, M.L.; Reddy, K.R. Evaluating rice for salinity using pot-culture provides a systematic tolerance assessment at the seedling stage. Rice 2019, 12. [CrossRef] 
50. Deshmukh, V.; Mankar, S.P.; Muthukumar, C.; Divahar, P.; Bharathi, A.; Thomas, H.B.; Rajurkar, A.; Sellamuthu, R.; Poornima, R.; Senthivel, S.; et al. Genome-Wide Consistent Molecular Markers Associated with Phenology, Plant Production and Root Traits in Diverse Rice (Oryza sativa L.) Accessions under Drought in Rainfed Target Populations of the Environment. Curr. Sci. 2018, 114, 329-340. [CrossRef]

51. Razzaque, S.; Elias, S.M.; Haque, T.; Biswas, S.; Jewel, G.M.N.A.; Rahman, S.; Weng, X.; Ismail, A.M.; Walia, H.; Juenger, T.E.; et al. Gene Expression analysis associated with salt stress in a reciprocally crossed rice population. Sci. Rep. 2019, 9. [CrossRef]

52. Stewart, G.; Larher, F. Accumulation of Amino Acids and Related Compounds in Relation to Environmental Stress. Amino Acids Deriv. 1980, 609-635. [CrossRef]

53. Ali, Q.; Athar, H.U.R.; Haider, M.Z.; Shahid, S.; Aslam, N.; Shehzad, F.; Naseem, J.; Ashraf, R.; Ali, A.; Hussain, S.M.; et al. Role of Amino Acids in Improving Abiotic Stress Tolerance to Plants. Plant Toler. Environ. Stress 2019, 175-204. [CrossRef]

54. Wang, M.; Liu, C.; Li, S.; Zhu, D.; Zhao, Q.; Yu, J. Improved Nutritive Quality and Salt Resistance in Transgenic Maize by Simultaneously Overexpression of a Natural Lysine-Rich Protein Gene, SBgLR, and an ERF Transcription Factor Gene, TSRF1. Int. J. Mol. Sci. 2013, 14, 9459-9474. [CrossRef] [PubMed]

55. Saeedipour, S. Stress-induced changes in the free amino acid composition of two wheat cultivars with difference in drought resistance. Afr. J. Biotechnol. 2012, 11, 9559-9565. [CrossRef]

56. Jackson, C.A.; Castro, D.M.; Saldi, G.A.; Bonneau, R.; Gresham, D. Gene regulatory network reconstruction using single-cell RNA sequencing of barcoded genotypes in diverse environments. eLife 2020, 9. [CrossRef]

57. Davidson, E.H.; Erwin, D.H. Gene Regulatory Networks and the Evolution of Animal Body Plans. Science 2006, 311, 796-800. [CrossRef] [PubMed]

58. Kærn, M.; Blake, W.J.; Collins, J. The Engineering of Gene Regulatory Networks. Annu. Rev. Biomed. Eng. 2003, 5, 179-206. [CrossRef]

59. Bonnaffoux, A.; Herbach, U.; Richard, A.; Guillemin, A.; Gonin-Giraud, S.; Gros, P.A.; Gandrillon, O. WASABI: A dynamic iterative framework for gene regulatory network inference. BMC Bioinform. 2019, 20. [CrossRef]

60. Sun, Y.; Dinneny, J.R. Q\&A: How do gene regulatory networks control environmental responses in plants? BMC Biol. $2018,16$. [CrossRef]

61. Emmert-Streib, F.; Dehmer, M.; Haibe-Kains, B. Gene regulatory networks and their applications: Understanding biological and medical problems in terms of networks. Front. Cell Dev. Biol. 2014, 2, 38. [CrossRef] [PubMed]

62. Arshad, O.A.; Datta, A. Towards targeted combinatorial therapy design for the treatment of castration-resistant prostate cancer. BMC Bioinform. 2017, 18, 5-15. [CrossRef]

63. Vundavilli, H.; Datta, A.; Sima, C.; Hua, J.; Lopes, R.; Bittner, M. Targeting oncogenic mutations in colorectal cancer using cryptotanshinone. PLoS ONE 2021, 16, e0247190. [CrossRef]

64. Timmermann, T.; González, B.; Ruz, G.A. Reconstruction of a gene regulatory network of the induced systemic resistance defense response in Arabidopsis using boolean networks. BMC Bioinform. 2020, 21. [CrossRef] [PubMed]

65. Venkat, P.S.; Narayanan, K.R.; Datta, A. A Bayesian Network-Based Approach to Selection of Intervention Points in the Mitogen-Activated Protein Kinase Plant Defense Response Pathway. J. Comput. Biol. 2017, 24. [CrossRef] [PubMed]

66. Vijesh, N.; Chakrabarti, S.K.; Sreekumar, J. Modeling of gene regulatory networks: A review. J. Biomed. Sci. Eng. 2013, 6, 223. [CrossRef]

67. Vundavilli, H.; Datta, A.; Sima, C.; Hua, J.; Lopes, R.; Bittner, M. Bayesian Inference Identifies Combination Therapeutic Targets in Breast Cancer. IEEE Trans. Biomed. Eng. 2019, 66. [CrossRef] [PubMed]

68. Karlebach, G.; Shamir, R. Modelling and analysis of gene regulatory networks. Nat. Rev. Mol. Cell Biol. 2008, 9, 770-780. [CrossRef] [PubMed]

69. Vundavilli, H.; Datta, A.; Sima, C.; Hua, J.; Lopes, R.; Bittner, M. Cryptotanshinone Induces Cell Death in Lung Cancer by Targeting Aberrant Feedback Loops. IEEE J. Biomed. Health Inform. 2020, 24. [CrossRef] [PubMed]

70. Kapoor, R.; Datta, A.; Sima, C.; Hua, J.; Lopes, R.; Bittner, M.L. A Gaussian Mixture-Model Exploiting Pathway Knowledge for Dissecting Cancer Heterogeneity. IEEE/ACM Trans. Comput. Biol. Bioinform. 2019, 17, 459-468. [CrossRef]

71. Sinoquet, C.; Mourad, R. Probabilistic Graphical Models for Next-generation Genomics and Genetics. In Probabilistic Graphical Models for Genetics, Genomics, and Postgenomics; Oxford University Press: Oxford, UK, 2014; pp. 1-16. [CrossRef]

72. Heckerman, D.; Breese, J. Causal independence for probability assessment and inference using Bayesian networks. IEEE Trans. Syst. Man Cybern. Part A Syst. Hum. 1996, 26. [CrossRef]

73. Borsuk, M.E.; Stow, C.A.; Reckhow, K.H. A Bayesian network of eutrophication models for synthesis, prediction, and uncertainty analysis. Ecol. Model. 2004, 173. [CrossRef]

74. Sevinc, V.; Kucuk, O.; Goltas, M. A Bayesian network model for prediction and analysis of possible forest fire causes. For. Ecol. Manag. 2020, 457, 117723. [CrossRef]

75. Neapolitan, R.E. Learning Bayesian Networks; Prentice Hall: Hoboken, NJ, USA, 2004; p. 433.

76. Kabli, R.; Herrmann, F.; McCall, J. A chain-model genetic algorithm for Bayesian network structure learning. In Proceedings of the 9th Annual Conference on Genetic and Evolutionary Computation-GECCO '07, London, UK, July 2007; ACM Press: New York, NY, USA, 2007; [CrossRef]

77. Scanagatta, M.; Salmerón, A.; Stella, F. A survey on Bayesian network structure learning from data. Prog. Artif. Intell. 2019, 8, 425-439. [CrossRef] 
78. Zhang, N.L. COMP538: Introduction to Bayesian Networks Lecture 6: Parameter Learning in Bayesian Networks. 2008. Available online: https://www.cse.ust.hk/bnbook/pdf/106.h.pdf (accessed on 4 April 2021).

79. Spiegelhalter, D. Lecture 6: Bayesian Estimation. 2016. Available online: http://www.statslab.cam.ac.uk/Dept/People/ djsteaching/S1B-17-06-bayesian.pdf (accessed on 4 April 2021).

80. Fan, Z.; Chin, A. Lecture 20-Bayesian Analysis. 2016. Available online: http://web.stanford.edu/class/stats200/Lecture20.pdf (accessed on 4 April 2021).

81. Orlof, J.; Bloom, J. Comparison of Frequentist and Bayesian Inference. 2014. Available online: https:/ / ocw.mit.edu/courses/ mathematics/18-05-introduction-to-probability-and-statistics-spring-2014/readings/MIT18_05S14_Reading20.pdf (accessed on 4 April 2021).

82. Storkey, A.J. Machine Learning and Pattern Recognition: Note on Dirichlet Multinomial. 2020. Available online: http: //www.inf.ed.ac.uk/teaching/courses/mlpr/assignments/multinomial.pdf (accessed on 4 April 2021).

83. Liu, H.; Wasserman, L. Bayesian Inference. In Statistical Machine Learning; Carnegie Mellon University: Pittsburgh, PA, USA, 2014; pp. 299-305.

84. Alvares, D.; Armero, C.; Forte, A. What Does Objective Mean in a Dirichlet-multinomial Process? Int. Stat. Rev. 2018, 86. [CrossRef]

85. Kelly, D.; Atwood, C. Finding a minimally informative Dirichlet prior distribution using least squares. Reliab. Eng. Syst. Saf. 2011, 96. [CrossRef]

86. Robert, C.P. Bayesian computational tools. Annu. Rev. Stat. Its Appl. 2014, 1, 153-177. [CrossRef]

87. Koller, D.; Friedman, F. Bayesian Parameter Estimation. In Probabilistic Graphical Models; MIT Press: Cambridge, MA, USA, 2009; pp. 738-739.

88. Bielza, C.; Larrañaga, P. Bayesian networks in neuroscience: A survey. Front. Comput. Neurosci. 2014, 8. [CrossRef]

89. Shimony, S.E. Finding MAPs for belief networks is NP-hard. Artif. Intell. 1994, 68, 399-410. [CrossRef]

90. Pearl, J. Probabilistic Reasoning in Intelligent Systems: Networks of Plausible Inference, 1st ed.; Morgan Kaufmann Publishers, INC: San Francisco, CA, USA, 1988.

91. Lozano-Pérez, T.; Kaelbling, K. 6.825 Techniques in Artificial Intelligence (SMA 5504); MIT OpenCourseWare: Cambridge, MA, USA, 2002.

92. Guo, H.; Hsu, W. A Survey of Algorithms for Real-Time Bayesian Network Inference; Technical Report; Association for the Advancement of Artificial Intelligence: Menlo Park, CA, USA,

93. Shwe, M.; Cooper, G. An empirical analysis of likelihood-weighting simulation on a large, multiply connected medical belief network. Comput. Biomed. Res. 1991, 24, 453-475. [CrossRef]

94. Russell, S.; Norvig, P. Artificial Intelligence: A Modern Approach, 3rd ed.; Prentice Hall: Hoboken, NJ, USA, 2010 ; pp. 533-535.

95. National Library of Medicine. National Center for Biotechnology Information; National Library of Medicine: Bethesda, Maryland, 1988.

96. Edgar, R. Gene Expression Omnibus: NCBI gene expression and hybridization array data repository. Nucleic Acids Res. 2002, 30. [CrossRef]

97. Barrett, T.; Wilhite, S.E.; Ledoux, P.; Evangelista, C.; Kim, I.F.; Tomashevsky, M.; Marshall, K.A.; Phillippy, K.H.; Sherman, P.M.; Holko, M.; et al. NCBI GEO: Archive for functional genomics data sets-update. Nucleic Acids Res. 2012, 41. [CrossRef]

98. Love, M.I.; Huber, W.; Anders, S. Moderated estimation of fold change and dispersion for RNA-seq data with DESeq2. Genome Biol. 2014, 15. [CrossRef]

99. Varet, H.; Brillet-Guéguen, L.; Coppée, J.Y.; Dillies, M.A. SARTools: A DESeq2- and EdgeR-Based R Pipeline for Comprehensive Differential Analysis of RNA-Seq Data. PLoS ONE 2016, 11. [CrossRef] [PubMed]

100. Conesa, A.; Madrigal, P.; Tarazona, S.; Gomez-Cabrero, D.; Cervera, A.; McPherson, A.; Szcześniak, M.W.; Gaffney, D.J.; Elo, L.L.; Zhang, X.; et al. A survey of best practices for RNA-seq data analysis. Genome Biol. 2016, 17. [CrossRef]

101. Wen, G. A Simple Process of RNA-Sequence Analyses by Hisat2, Htseq and DESeq2. In Proceedings of the 2017 International Conference on Biomedical Engineering and Bioinformatics-ICBEB, Bangkok, Thailand, September 2017; ACM Press: New York, NY, USA, 2017. [CrossRef]

102. Jeong, H.H.; Liu, Z. Are HHV-6A and HHV-7 Really More Abundant in Alzheimer's Disease? Neuron 2019, 104. [CrossRef]

103. Nagarajan, R.; Scutari, M.; Lèbre, S. Bayesian Networks in R; Springer: New York, NY, USA, 2013. [CrossRef]

104. Scutari, M. Learning Bayesian Networks with the bnlearn R Package. J. Stat. Softw. 2010, 35. [CrossRef]

105. R Core Team. R: A Language and Environment for Statistical Computing; R Foundation for Statistical Computing: Vienna, Austria, 2017. 